\title{
PANDUAN LOKASI DAN AKOMODASI WISATA BERBASIS ANDROID DI YOGYAKARTA
}

\author{
Nurul Mega Saraswati ${ }^{1}$, Budi Suhendro ${ }^{2}$ \\ Program Pasaca Sarjana Magister Teknik Informatika, Universitas Islam Indonesia ${ }^{\text {, }}$ \\ Jl. Kaliurang Km.14,5, Sleman, Yogyakarta, 55584 \\ Sekolah Tinggi Teknologi Nuklir Batan ${ }^{2}$, \\ Babarsari, Yogyakarta \\ E-Mail :nurul.mega.s@gmail.com ${ }^{1}$,sudroib@gmail.com²
}

\begin{abstract}
Application guides tourist sites in Yogyakarta, is a system that provides convenience to the traveler's reference to tourist sites and public facilities such as gas stations, hotels, restaurants and souvenier shops on the application. With this application accessing information to become more effective and efficient use of smartphones to better facilitate the search of tourist sites that use LBS, featuring the categories of travel (natural tourism, education and cultural / historical), provide search facility tourist sites based on cost-owned using minimal android app 2.2 (Froyo). The method of using the system development model of HIPO and relation table, the implementation phase of software development using Windows7, Javascript and MySQL database. Android based applications can facilitate the user to travel to locations with existing costs.
\end{abstract}

Keywords : LBS, Android, Tourism Yogyakarta, Applications and SQLITE.

\section{PENDAHULUAN}

Pariwisata adalah suatu perjalanan liburan untuk menghilangkan penat yang ada setelah melakukan aktivitas yang dilakukan setiap hari ke suatu daerah dengan berpergian dapat membuat mereka nyaman dan tenang untuk merefreskan suasana hati dan pikiran. Daerah Istimewa Yogyakarta termasuk daerah rekreasi banyak pengunjungnya, dilihat berdasarkan pengunjung di bulan Juli 2016 Badan Statistik Provinsi DIY menunjukan 61,16\%. Provinsi DIY memiliki berbagai macam ragam obyek wisata dan panaroma yang indah, seperti wisata alam, wisata budaya, wisata pendidikan, wisata malam dan wisat kuliner. Teknologi Informasi yang saat ini semakin maju dan pesat, berbagai macam kebutuhan manusia dan membantu aktivitas manusia. Teknologi untuk menentukan GPS dengan konsep LBS (Location Based Services) berupa suatu layanan informasi yang harus menggunakan akses internet dan smartphone untuk menentukan rute lokasi yang akan dituju (Dito, 2012).

Kendala yang kadang dihadapi oleh wisatawan berupa ketidaktahuan lokasi- lokasi yang akan dikunjungi, kebingungan akan adanya rute - rute obyek wisata, kurangnya informasi tentang seberapa biaya yang akan dikeluarkan untuk melakukan liburan. Mengatasi masalah tersebut, di perlukan sebuah aplikasi yang dapat memberikan referensi mengenai daftar obyek wisata di DIY beserta rute perjalanan dengan menggunakan pencariaan obyek wisata berdasarkan biaya yang dimiliki wisatawan.

Aplikasi dibuat untuk sarana dalam memberikan referensi mengenai daftar obyek wisata yang ada di Yogyakarta beserta rutenya, menggunakan GPS dengan konsep LBS yang aplikasi tersebut dapat melakukan pencarian daftar obyek wisata berdasarkan biaya yang dimiliki wisatawan.

\section{LANDASAN TEORI}

\subsection{Location Based Service (LBS)}

LBS adalah layanan IP nirkabel dan informasi geografis untuk membantu memberi petunjuk lokasi yang dituju kepada pengguna. Pada LBS terdapat tiga titik temu teknologi yang dikenal sebagai New Information and Communication System 
(NICTS) yang berupa Geographical Information System (GIS), Internet and Mobile Devices. Cara kerja LBS pertama adalah melakukan indentifikasi user action (perilaku pengguna) dan informasi yang dibutuhkan, permintaan yang diinginkan pasti akan berbeda sesuai dengan kebiasaan, karakter pengguna dan informasi yang dikirim. Setelah itu, proses akan menampilkan informasi yang dilakukan pada sistem LBS.

\subsection{Software Pendukung}

\section{a. SQLite}

SQLite menurut Kurniawan (2009) adalah sebuah manajemen basis data relation yang bersifat ACID-comlaint dan terdapat standar kode pustaka yang lebih kecil dan ditulis menggunakan bahasa C. SQLite termasuk integrasi dari seluruh sistem untuk komunikasi dengan program yang opensource merupakan lightweight database sebagai alternatif $M y S Q L$ agar lebih stabil. Mekanismenya komunikasi menggunakan API melalui bahasa pemrograman agar dapat mengurangi overhead, latency times dan lebih sederhana. Android memiliki database yang terstruktur pada setiap aplikasi yang menggunakan SQLite.

\section{b. Eclipse}

Eclipse menurut Khannedy (2007) adalah Integrated Development Environment (IDE) yang gratis dan open source bisa sebagai pengembangan perangkat lunak dengan komponen plug-in Android development Tool (ADT) pada pengembangan software berbasis Android.

\section{c. Android SDK}

Android SDK (Software Development Kit) adalah alat bantu programmer mengembangkan aplikasi berbasis Google Android dengan menggunakan tool API (Application Programming Interface) dan bahasa pemrogaman Java. (Safaat, 2011).

\section{METODOLOGI PENELITIAN}

3.1. Analisis Kebutuhan Input, Output dan Proses

\section{a. Kebutuhan Input}

Input adalah bentuk masukan yang biasa berupa data yang telah ada dan dibutuhkan oleh perangkat lunak untuk mencapai tujuan yang diinginkan. Data masukan yang dibutuhkan pada sistem antara lain :

- Data Wisata

Data ini berupa informasi-informasi tentang tempat-tempat wisata di Yogyakarta.

- Pencarian Input-an data dalam pencarian disini berdasarkan nama, kategori dan bisa juga biaya yang dimiliki. Data nama berisikan nama tempat wisata. Kategori berupa data wisata alam, wisata budaya / sejarah dan wisata pendidikan.

- Fasilitas Umum

Data ini berupa informasi tentang fasilitas umum yang ada di Yogyakarta. Fasilitas umum disini seperti SPBU, hotel, restoran dan toko souvenier / oleh - oleh.

\section{b. Kebutuhan Output}

Output yang dihasilkan berupa informasi-informasi dari suatu proses, baik berupa data maupun informasi yang telah diolah. Output dari aplikasi ini berupa :

- Data Wisata

Output yang dihasilkan berupa nama wisata, alamat wisata, kategori wisata, deskripsi, gambar, biaya masuk untuk ke obyek wisata dan peta rute.

- Data SPBU

Output dalam data SPBU berupa nama SPBU, alamat dan peta rute tempat SPBU berada.

- Data Hotel

Output data hotel berupa nama hotel, alamat, gambar, reating (level) dan peta rute.

- Data Souvenier

Output dalam data souvenier berupa nama toko, alamat, gambar dan peta rute. 
- Data Restoran

Output restoran berupa nama restoran, alamat, gambar dan peta rute.

- Pencarian

Output yang dihasilkan berupa nama list list lokasi tempat wisata di Yogyakarta dari semua kategori wisata.

\section{c. Kebutuhan Proses}

Berdasarkan kebutuhan yang telah dilakukan, proses - proses yang akan dilakukan oleh sistem adalah :

- Proses pencarian obyek wisata dan menampilkan lokasi tersebut berdasarkan pada biaya yang dimiliki wisatawan untuk memasuki lokasi wisata.

- Proses pembuatan rute ke obyek wisata untuk membantu pengguna menuju lokasi wisata dengan tepat.

\subsection{Perancangan Sistem}

\section{a. Perancangan Sistem Dengan HIPO}

Berikut ini adalah diagram HIPO yang menunjukkan menu - menu yang terdapat dalam aplikasi, sehingga dapat mengetahui cara kerja sistem melalui diagram. Diagram HIPO dapat ditunjukan pada gambar 1.

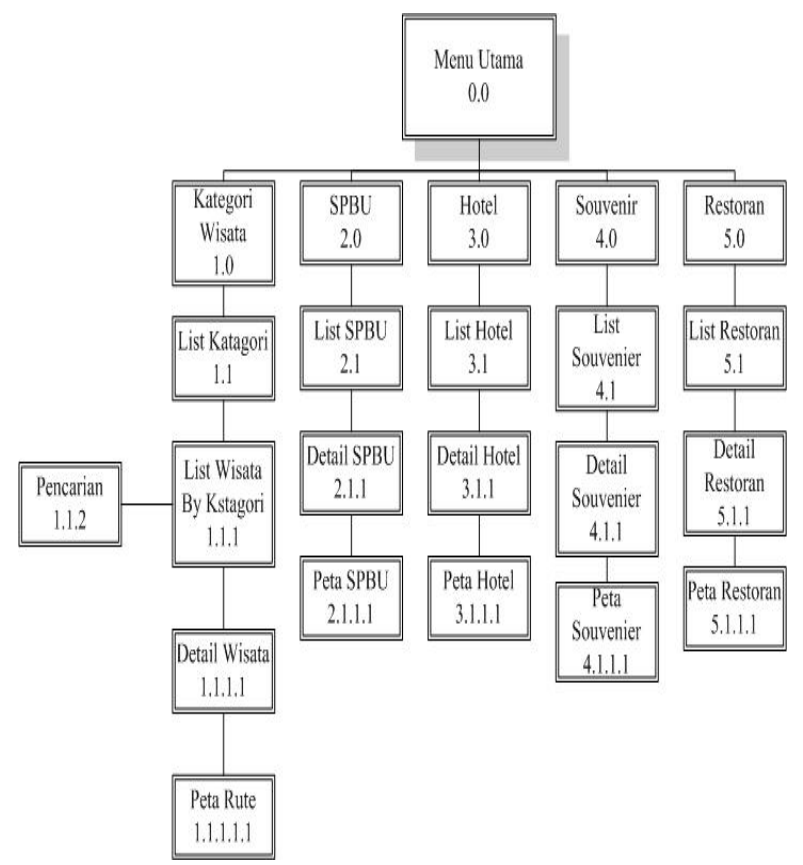

Gambar 1 Diagram HIPO.

\section{b. ERD (Entity Relationship Diagram)}

Dalam membuat aplikasi dibutuhkan ERD untuk mengetahui hubungan setiap entitas dari atribut. Di bawah ini dapat dilihat ERD dari setiap entitas.

\section{Kategori Wisata}

ERD di kategori wisata memiliki atribut nm_kategori, id_kategori, id_wisata, gambar, alamat, deskripsi, biaya_masuk, longitude, latitude. ERD dapat dilihat pada gambar 2 .

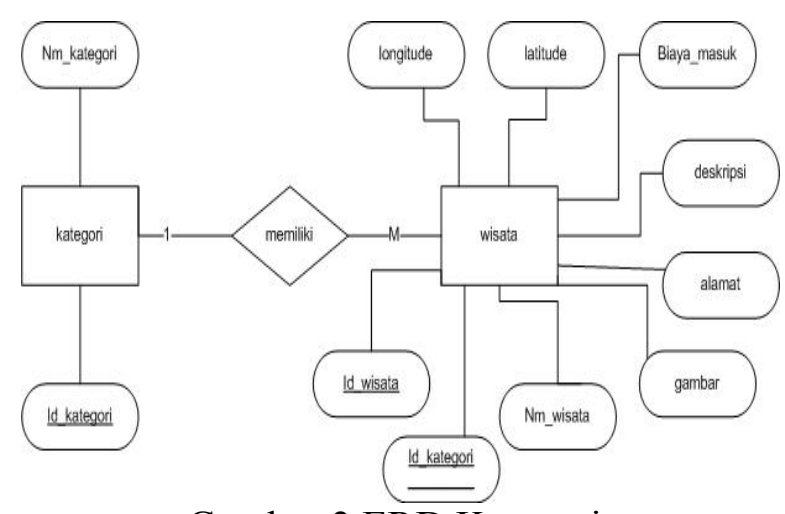

Gambar 2 ERD Kategori.

2. SPBU

ERD di SPBU memiliki atribut id_SPBU, nm_SPBU, alamat, longitude, latitude. ERD dapat dilihat pada gambar 3.

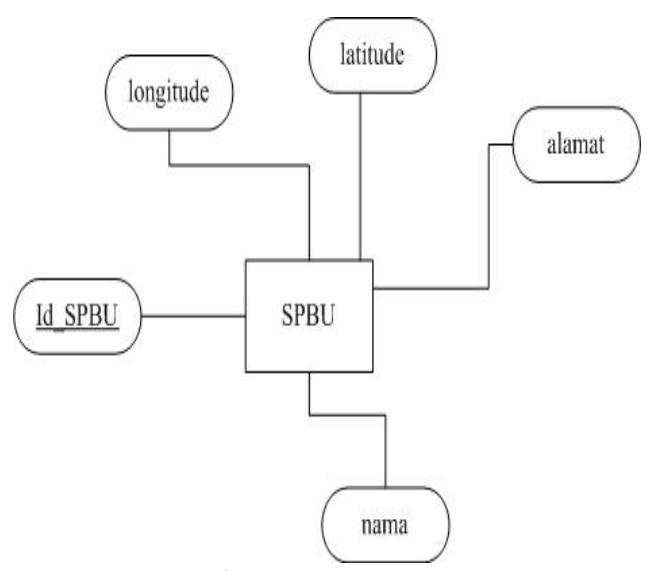

Gambar 3 ERD SPBU

3. Hotel

ERD di hotel memiliki atribut nm_hotel, id_hotel, gambar, alamat, reating, longitude, latitude. ERD dapat dilihat pada gambar 4. 


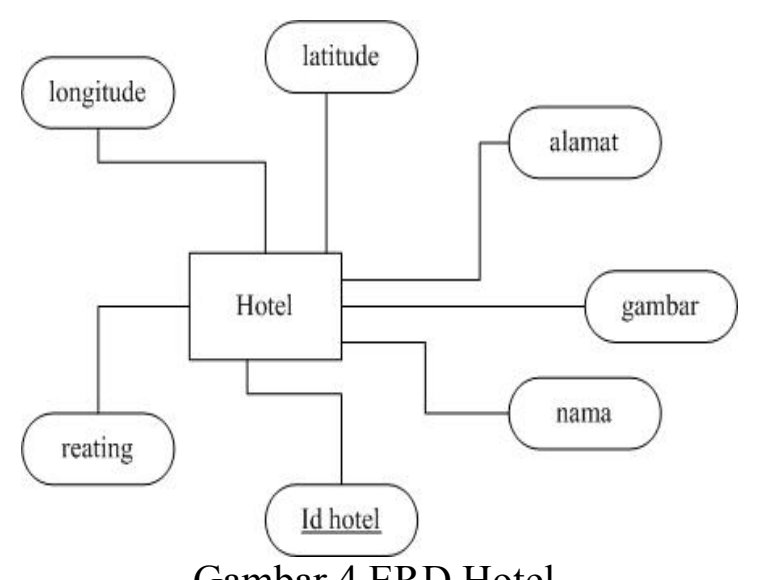

Gambar 4 ERD Hotel.

\section{Souvenier}

ERD di souvenier memiliki atribut nm_souvenier, id_restoran, alamat, gambar, longitude, latitude. ERD dapat dilihat pada gambar 5 .

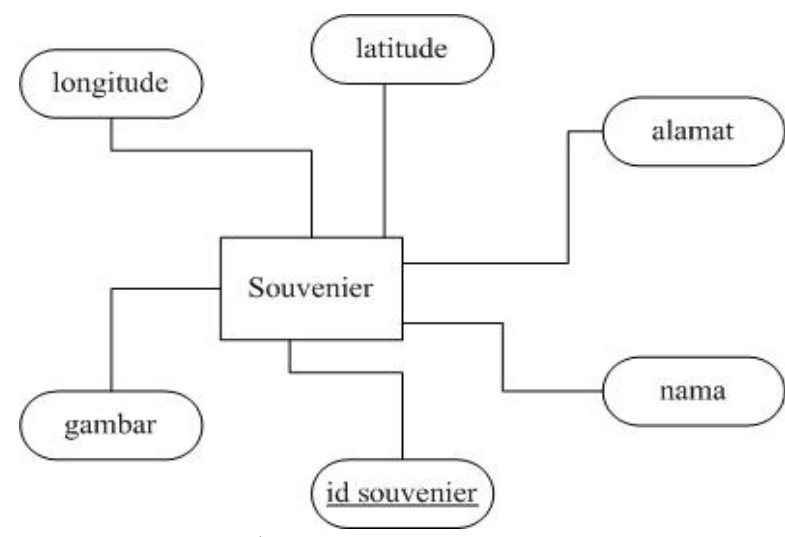

Gambar 5 ERD Souvenier.

5. Restoran

ERD di restoran memiliki atribut $\mathrm{nm}$-restoran, id_restoran, alamat, gambar, longitude, latitude. ERD dapat dilihat pada gambar 6 .

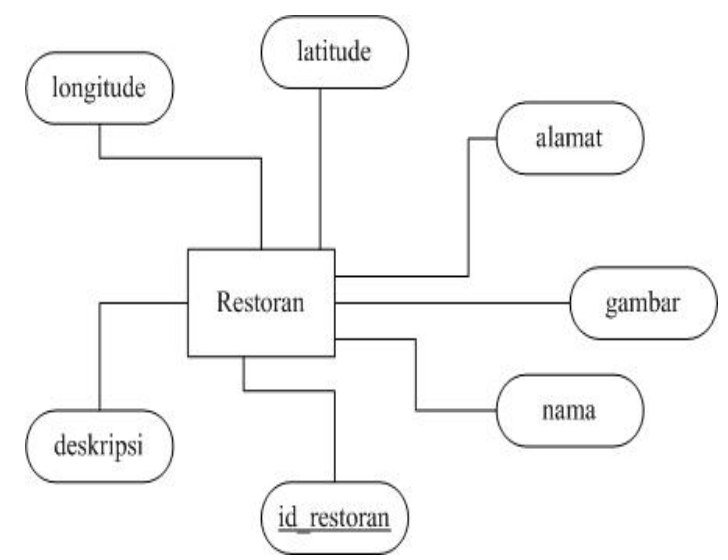

Gambar 6 ERD Restoran.

\subsection{Alur Pembuatan}

Pembuatan aplikasi ini terdiri dari beberapa tahap, dimana pada tiap tahapan tersebut adalah bagian dari perancangan aplikasi. Adapun rancangan halaman tersebut, dapat dilihat pada gambar 7 .

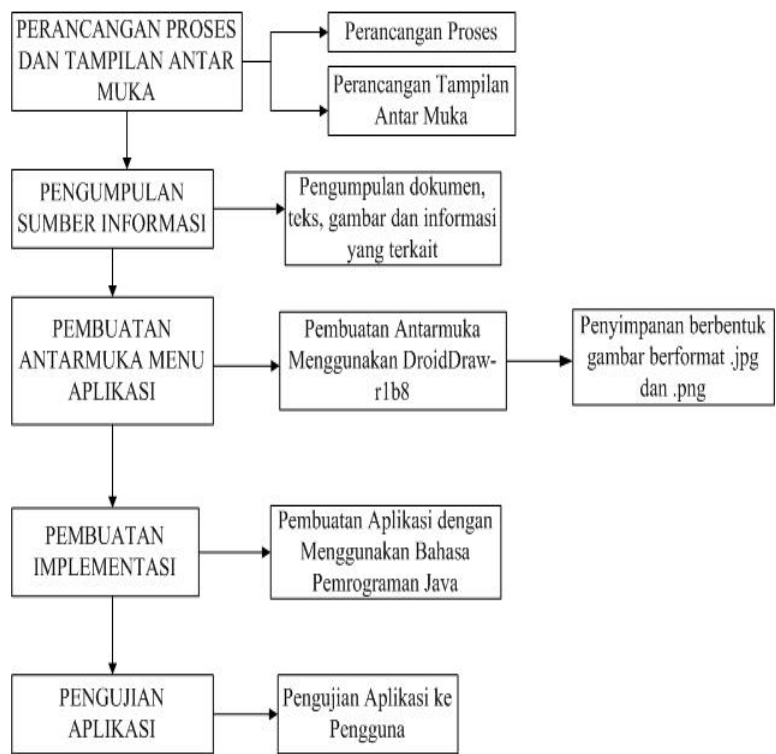

Gambar 7 Alur Pembuatan Aplikasi.

1. Perancangan Proses dan Tampilan Antarmuka

Pertama melakukan proses secara garis besar untuk merancang aplikasi dan antarmuka aplikasi. Kemudian akan membentuk suatu aplikasi yang berinteraksi didalamnya.

2. Pengumpulan sumber Informasi

Pada pengumpulan informasi ini, meliputi segala bentuk dokumen baik data biaya masuk ke obyek wisata, data fasilitas umum, gambar, peta ataupun modul yang digunakan untuk kelengkapan informasi.

3. Pembuatan Antarmuka Menu Aplikasi dan Simulasi

Desain tombol, menu dan background dibuat menggunakan DroidDraw-rlb8.

4. Pembuatan Implementasi

Pembuatan aplikasi tersebut menggunakan bahasa pemrograman Java yang akan di singkronisasikan dengan sistem operasi Android.

5. Pengujian Aplikasi

Tahap terakhir adalah menguji aplikasi yang telah dibuat untuk mengetahui 
keberhasilan aplikasi tersebut dalam penggunaannya sebagai media belajar.

\section{HASIL DAN PEMBAHASAN}

Tahap implementasi Aplikasi Panduan Lokasi dan Akomodasi Wisata di D.I Yogyakarta memiliki kemajuan dari tahap perancangan sampai dengan tahap implementasi yang berdasarkan pada perencanaan. Implementasi aplikasi ini bertujuan mempermudah wisatawan mengetahui lokasi wisata, biaya masuk ke lokasi wisata dan fasilitas umum yang dilalui menuju lokasi yang akan dituju. Aplikasi yang dibuat sebatas informasi biaya masuk, deskripsi tempat wisata, informasi fasilitas umum, informasi posisi user, informasi biaya yang dimiliki untuk masuk ke lokasi wisata dan pencarian rute dari posisi user menuju lokasi wisata.

Pada tahap ini merupakan tampilan aplikasi yang telah dirancang dan dibuat dalam keadaan sesungguhnya, pengguna akan mengetahui aplikasi dapat berjalan dengan baik dan output sesuai dengan perancangan atau tidak.

\section{Halaman Utama}

Tampilan awal dalam aplikasi dan menampilkan beberapa menu tentang informasi obyek wisata, hotel, SPBU, toko souvenier dan restoran (Gambar 8).

2. Halaman Kategori

Pada menu pilihan kategori, akan menampilkan beberapa menu kategori wisata seperti wisata alam, wisata pendidikan, wisata sejarah atau budaya (Gambar 9).

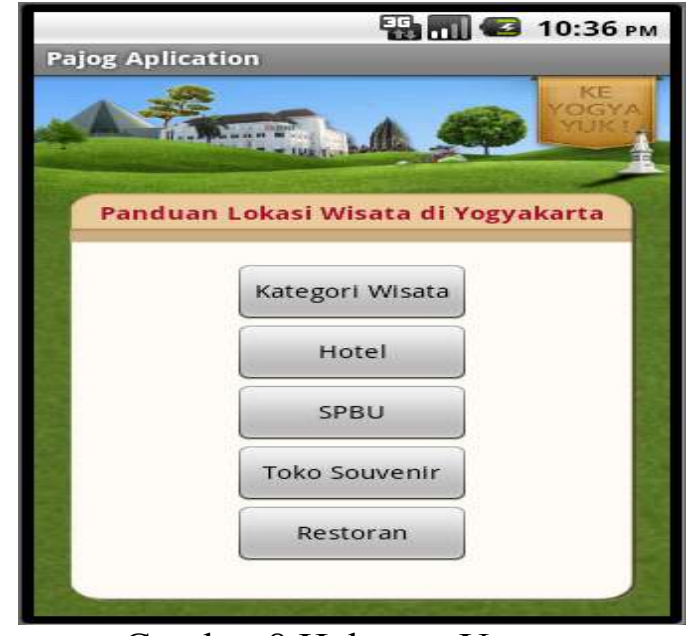

Gambar 8 Halaman Utama.

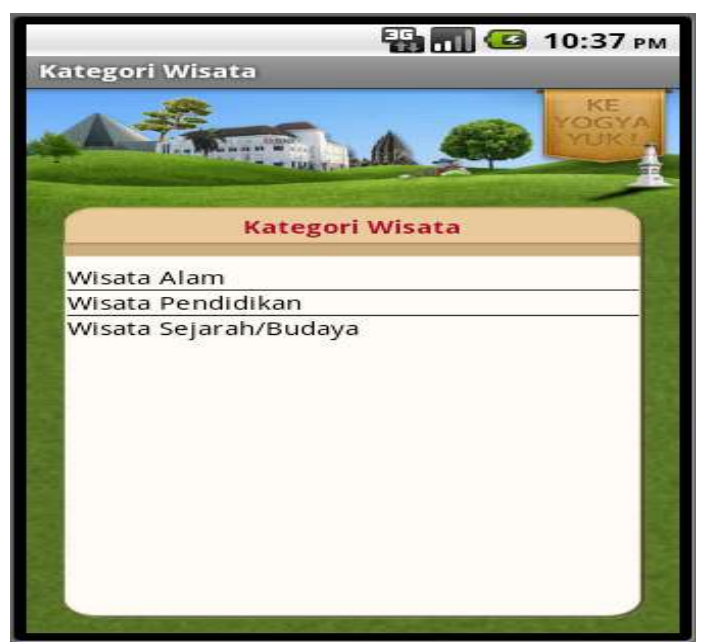

Gambar 9 Halaman Kategori.

3. Halaman Wisata

Sesudah memilih kategori, aplikasi akan memberikan alternatif-alternatif lokasi wisata yang ada di D.I Yogyakarta (Gambar 10).

4. Halaman Pencarian

Halaman yang menampilkan pencarian lokasi wisata berdasarkan biaya yang dimiliki, tetapi informasi biaya disini hanya sebatas biaya masuk ke lokasi wisata. Pengisian data berupa angka (Gambar 11). 


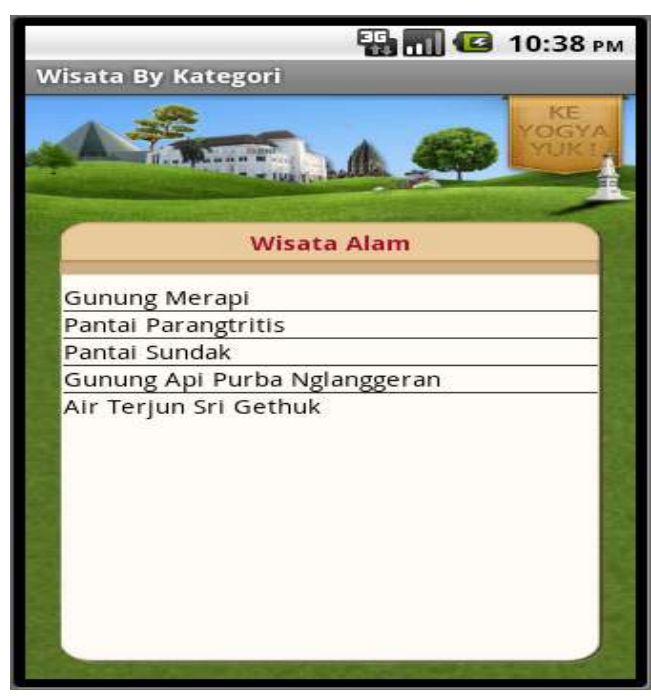

Gambar 10 Halaman Wisata.

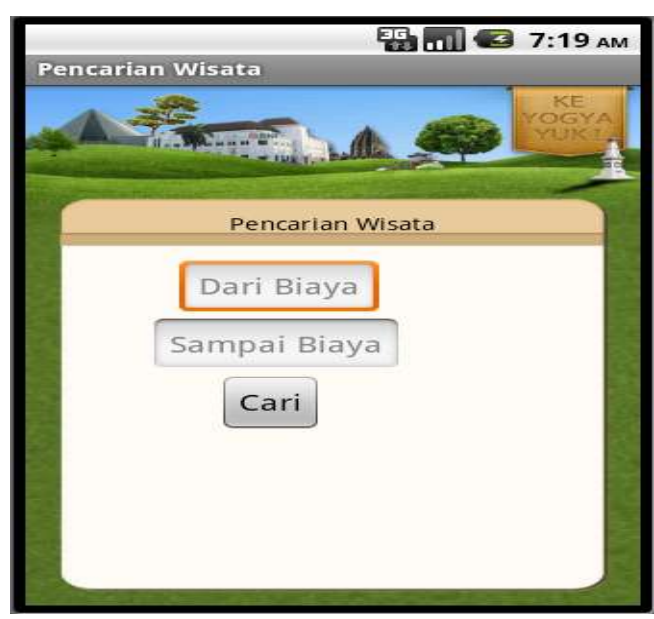

Gambar 11 Halaman Pencarian.

5. Halaman Hasil Pencarian

Halaman dari hasil pencarian dan disini menampilkan list nama-nama lokasi wisata dengan biaya yang dicari (Gambar 12).

6. Halaman Detail Wisata

Menampilkan informasi - informasi tempat wisata yang berisi nama, alamat, biaya masuk, foto dan deskripsi singkat tentang lokais yang akan dikunjungi. Terdapat tombol Map untuk mengetahui rute (Gambar 13).

7. Halaman Peta Rute

Berisi tentang rute yang akan dituju agar rute perjalanan menuju ke lokasi wisata agar lebih mudah (Gambar 14).

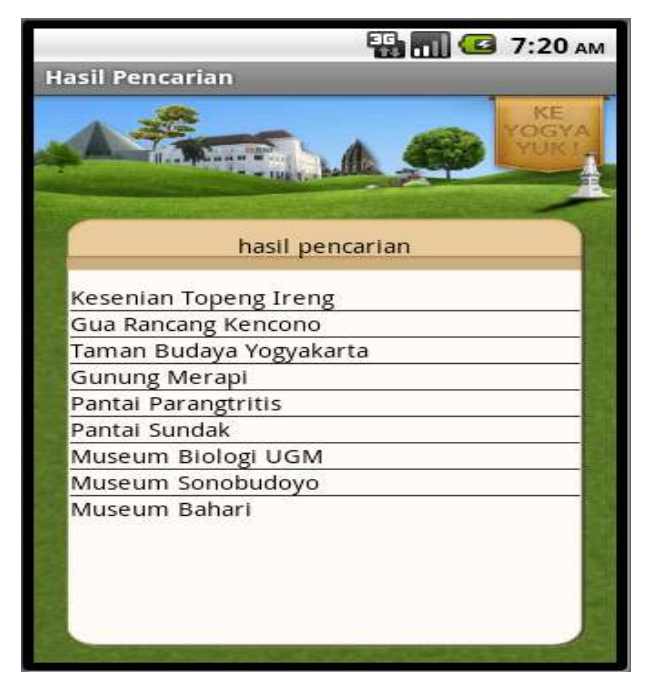

Gambar 12 Halaman Hasil Pencarian.

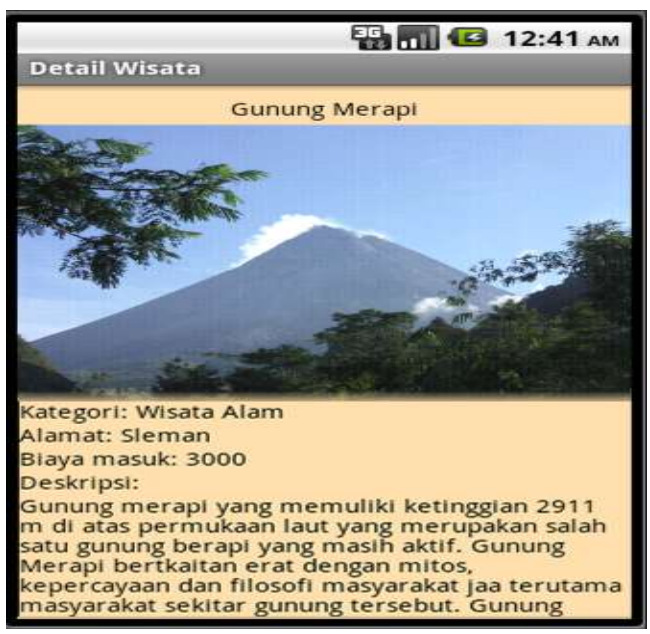

Gambar 13 Halaman Detail.

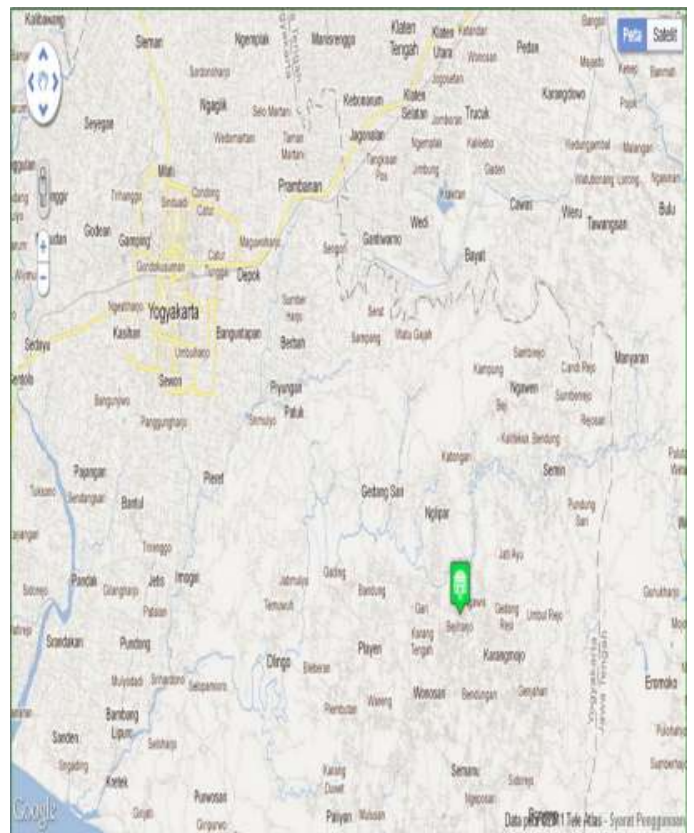

Gambar 14 Halaman Peta Rute. 
Tabel 1 Hasil Pengujian Berbagai Merk dan Versi Smartphone

\begin{tabular}{|c|c|c|c|c|}
\hline No & Merk HP & Versi & Ukr. & Hasil Pengujian \\
\hline 1 & $\begin{array}{c}\text { Samsung } \\
\text { Galaxy Mini }\end{array}$ & $\begin{array}{c}2.2 \\
(\text { Froyo })\end{array}$ & 3.14 inci & $\begin{array}{l}\text { Tatanan menu menjadi } \\
\text { sempit dari satu menu ke } \\
\text { menu lain karena standar } \\
\text { menggunakan layar } 3.5 \text { inci. } \\
\text { (Gambar 15) }\end{array}$ \\
\hline 2 & Xperia Miro & $\begin{array}{c}4.0 \\
\text { (Ice Cream } \\
\text { Sandwich) }\end{array}$ & 3.5 inci & $\begin{array}{l}\text { Tampilan sesuai target } \\
\text { karena sesuai resolusi dan } \\
\text { berjalan dengan baik } \\
\text { menggunakan LBS (Gambar } \\
\text { 16). }\end{array}$ \\
\hline 3 & Lenovo S720 & $\begin{array}{c}4.0 \\
\text { (Ice Cream } \\
\text { Sandwich) }\end{array}$ & 4.5 inci & $\begin{array}{l}\text { Meskipun di atas versi } 2.2 \\
(\text { Froyo), tatanan menu } \\
\text { menjadi lebih lebar karena } \\
\text { layar yang terlalu pajang } \\
\text { (Gambar 17). }\end{array}$ \\
\hline
\end{tabular}

\subsection{Hasil Pengujian}

Pengujian aplikasi dilakukan berbagai versi, tipe dan lebar layar smartphone, berikut hasil tampilan pengujian pada tabel 1.

Pengujian di berbagai perangkat dan versi Android memiliki kelebihan dan kekurangan, berikut kekurangan dan kelebihan dari aplikasi tersebut yaitu :

1. Kelebihan :

a. Tampilan user friendly yang memudahkan dalam pengoprasian.

b. Aplikasi bersifat mobile sehingga bisa di bawa dan digunakan dimana saja.

c. Lokasi user dapat diperoleh secara otomatis oleh GPS.

d. Aplikasi berkerja dengan cepat karena sistem offline, kecuai pada bagian GPS.

2. Kekurangan

a. User tidak dapat menambah informasi - informasi tentang lokais wisata dan fasilitas umum di D.I. Yogyakarta.

b. Tampilan akan tidak rapi karena standar tampilan layar adalah 3.5 inci. c. Jaringan untuk akses GPS minimal $3 \mathrm{G}$.

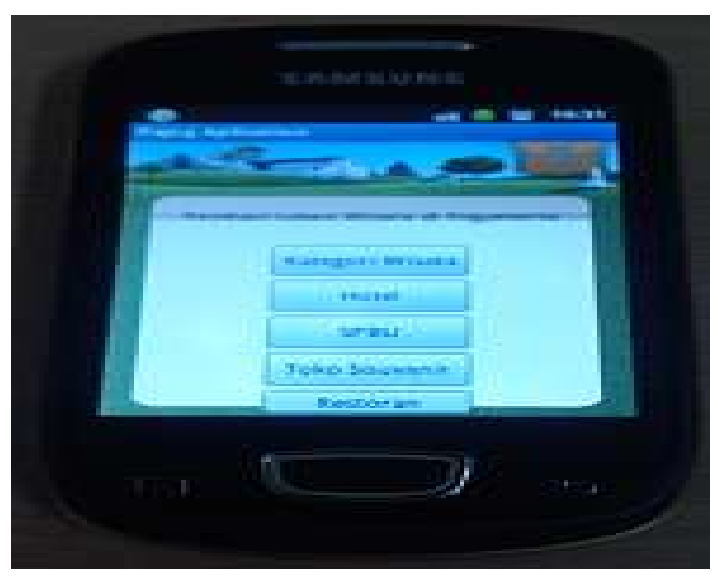

Gambar 15 Pengujian pada Samsung Galaxy Mini.

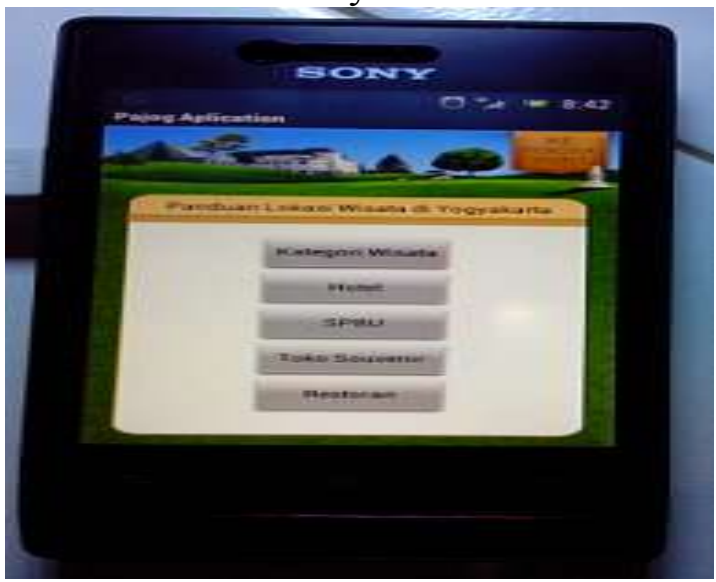

Gambar 16 Pengujian pada Xperia Miro. 


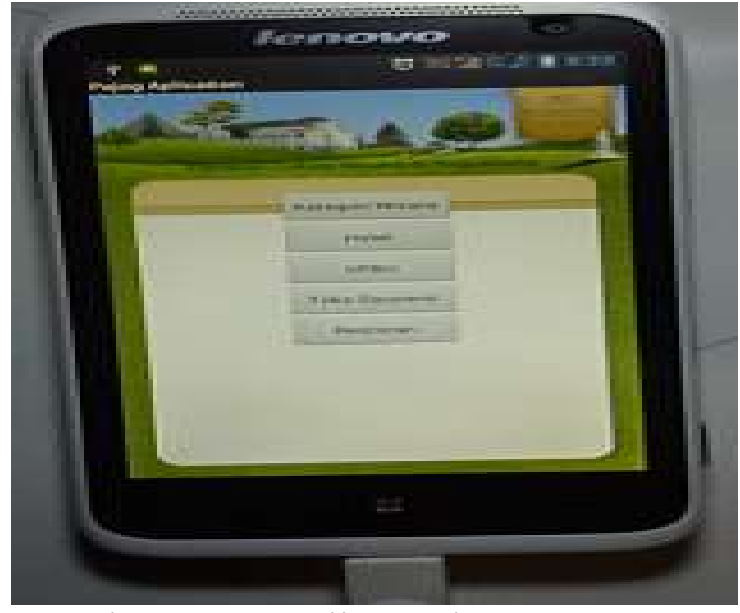

Gambar 17 Pengujian pada Lenovo S720.

\section{KESIMPULAN}

Berdasarkan hasil penelitian, analisis, perancangan sistem dan pembuatan aplikasi sampai dengan tahap penyelesaian, maka dapat ditarik beberapa kesimpulan antara lain sebagai berikut :

1. Aplikasi panduan lokasi wisata memberikan informasi tempat wisata yang dibutuhkan wisatawan berdasarkan kategori wisata alam, wisata pendidikan dan wisata budaya atau sejarah.

2. Aplikasi panduan lokasi wisata ini memberikan tampilan GPS menggunakan metode LBS, sehingga tampilan mudah dimengerti oleh user.

3. Penyusunan aplikasi panduan lokasi wisata dibuat menarik agar pengguna mudah mencari informasi yang diinginkan dari aplikasi ini.

4. Aplikasi panduan lokasi wisata berjalan dengan baik dengan sistem operasi android mulai versi 2.2 (Froyo) dan selanjutnya.

5. Aplikasi akomodasi wisata memberikan kemudahan wisatawan dalam menentukan lokasi wisata dengan budget yang dimiliki.

\section{DAFTAR PUSTAKA}

Amarullah, A. Mengenal Google Map. Retrieved from http://amarullz.blog.unikom.ac.id/me ngenal-google-map.bl, 2010.

Ardiansyah. Mengenal Location Based Service (LBS). Retrieved from http://blog.uad.ac.id/ardi/2011/04/04 /mengenal-location-based-servicelbs/comment-page-1/, 2011.

Daishz. GPS. Retrieved from http://www.daishz.com/2010/09/andr oid-adalah.html, 2010.

Daishz. Jenis dan Versi OS Android, Perbedaan Serta Fitur dan Kemampuannya. Retrieved from http://www.teknokers.com/2011/02/je nis-versi-os-android-perbedaanserta.html, 2011.

Dito. Pengertian GPS. Retrieved from ditoaw2.blogspot.com/2012/11/penge rtian-gps 4.html, 2012.

Geografis DIY. Retrieved from http://www.pemda-diy.go.id/, 2010.

Komutta. Komutta Aplikasi Informasi Angkutan Umum Jakarta. Retrieved from

http://portal.paseban.com/review/542 5/komutta/, 2012.

Kondisi Geografis. Retrieved from http://www.pemda-diy.go.id/, 2009.

Kurniawan, E. Mengenal SQLite. Retrieved from

http://kesibubby.wordpress.com/2009 /02/2013/mengenal-sqlitel, 2009.

Mahadisuta. Macam - Macam GPS. Retrieved from http://blog.fastncheap.com/seacrh/ma cama-macam-gps-super-spring, 2012. 
Morgana. Bagaimana Cara Kerja GPS. Retrieved from http://ahlikompie.com/bagaimanacara-kerja-gps-817.html, 2010.

Nata, W. Pariwisata menurut para Ahli. Retrieved from http://wiranatawira.blogspot.com/, 2009.

Putra, A. Nusantara Beta. Retrieved from http://www.aplikanologi.com/produkt ivitas/darisini-tentukan-tujuanlokasimu/, 2011.

Wartawarga. Pengertian Pariwisata, Kepariwisataan, dan Perjalanan Pariwisata. Retrieved from http://wartawarga.gunadarma.ac.id/2 010/10/pengertian-pariwisatakepariwisataan-dan-perjalananpariwisata/, 2010. 